Makale Geliş Tarihi: 12.05.2019

Makale Kabul Tarihi: 23.06.2019

\title{
ÇAND Û ŞARISTANÎYA KURDÊN MERWANî DI TARÎXU MEYYAFARIQÎNÊ YA ÎBNU'I-EZREQ DA ${ }^{1}$
}

\begin{abstract}
Ahmet SEYAR $\dot{I}^{2}$
KURTE

Îbnu'l-Ezreq el-Fariqî di sedsala XII'an da, di serdema Artûqîyan da, jîyaye û di dezgehên rêvebirîya dewletê da xebitîye. Fariqî di berhema xwe ya bi navê Tarîxu Meyyafariqînê da derheqê çand û şaristanîya kurdên Merwanî da gelek agahîyên girîng dane. Ev berhem di warê siyasî, sosyolojî, mîmarî, hiqûq û aborîyê da dikare gelek alîyên vê serdemê ronî bike û rê li ber xebatên nû veke. Di vê xebatê da agahîyên di warê çand û şaristanîya kurdên Merwanî, yên ku di Tarîxu Meyyafariqînê da derbas dibin, hatine tesbîtkirin û şîrovekirin. Di vê çarçoveyê de di warê rêvebirîya dewletê de taybetîya mîran û șewaza derketina wan a ser textê mîrîtîyê, taybetî û peywirên wezîr, walî û karê nivîsvanan, taybetîyên pergala hiqûqê û qazîyan û rê û rêbaza darizandinê hatiye vegotin. Derheqê artêşa kurdên Merwanî û çekên ku di vê artêşê da hatine bikaranîn da agahî hatine dayîn. Behsa kevneşopî û tore, bîr û bawerîyên di serdema kurdên Merwanî da hatiye kirin. Herwiha agahîyên derheqê avahîyên mîmarî yên ku li vê serdemê hatine çêkirin da û çalakîyên di warê aborî û bazirganîyê û weqfên alîkarîyê da hatine tesbîtkirin û şîrovekirin.

Peyvên Sereke: Kurdên Merwanî, Çand û şaristanî, Tarîxu Meyyafariqîn, Îbnu'lEzreq el-Fariqî.

\footnotetext{
${ }^{1}$ Vê gotarê bingeha xwe ji beșeke teza min a mastirê girtiye. Ev tez bi navê "Kurdên Merwanî di Tarîxu Meyyafariqîn a Îbnu'l-Ezreq de" di sala 2016an de li Zanîngeha Mêrdîn Artukluyê di beşa Ziman û Çanda Kurdî de hatiye nivîsîn.

${ }^{2}$ Zanîngeha Bîngolê- Beşa Ziman û Edebiyata Kurdî - Xwendekarê Doktorayê. ehmedseyari@gmail.com ORCID: 0000-0001-2345-6789
} 


\title{
Îbnu'l-Ezrak'ın Tarihu Meyyafarıkin Adlı Eserinde Mervanilerin Kültür ve Medeniyetleri
}

\begin{abstract}
ÖZET
Îbnu'l-Ezrak el-Farıki 12. yüzyılda Artuklular döneminde yaşamıș ve bazı devlet kademelerinde görev almıştır. Farıki Tarihu Meyyafarıkin adlı eserinde Mervanilerin kültür ve medeniyetleri hakkında çok önemli bilgiler vermektedir. $\mathrm{Bu}$ eser siyasi, sosyolojik, mimari, hukuki ve ekonomik açıdan bu dönemin birçok yönünü aydınlatıyor ve bu alanda yapılacak birçok çalışmaya katkı sağlayabilir. Bu çalışmada Mervani Kürtlerinin oluşturdukları ve Tarihu Meyyafarıkin'de yer alan kültür ve medeniyet ele alınmıştır. Bu çerçevede devlet yönetiminde emirlerin özellikleri ve tahta çıkış şekilleri, vezir, vali ve divan idaresi hakkında bilgi verilmiştir. Hukuk sistemi ve kadıların özellikleri ve yargılama şekilleri ele alınmıştır. Mervani Kürtlerinin ordusunın özellikleri ve ordunun kullandığı silahlar hakkında bilgi yer almaktadır. Ayrıca bu çalışmada Mervani dönemine ait bina, kalıntı sur, burc, saray, mesire, kubbe, cami ve hastane gibi mimari eserler hakkında bilgi mevcuttur. Yanı sıra, çalışmada Mervani Kürtlerinin adet, gelenek, görenek ve inanışlar, vakıf ve yardımlaşma, ekonomi ve ticari faaliyetler hakkında bilgiler yer almaktadir.
\end{abstract}

Anahtar Kelimeler: Mervani Kürtleri, kültür ve medeniyet, Tarihu Meyyafarıkin, İbnu'l-Ezrak el-Farikî.

\section{The Culture and Civilisation of Merwant Kurds in The Work Named Tarīkh al-Mayyāfāriqīn by Îbnu'l-Ezreq}

\begin{abstract}
Ibn al-Azraq al-Fariqi lived in the 12th century Artuqid period and served in some state levels. In his work Tarīkh al-Mayyāfäriqīn, Farıqi gives very important information about the culture and civilization of the Marwanis. This work can contribute to many studies in this field by illuminating many aspects of this period in terms of political, sociological, architectural, legal and economic aspects. In this study, the culture and civilization established by the Marwani Kurds in Tarīkh alMayyāaanriqīn are analyzed. In this context, information about the characteristics of the ameers in the administration of the state and how they came to the throne and information about viziers, valis and divan works is given. The legal system, the characteristics of the kadis and their ways of judging are explained. Information is given on the features of the army of the Marwani Kurds and the special weapons they used. Explanations have been provided about the buildings, remains and architectural works of this period. In addition to these, certain knowledge has been presented about the city walls, palaces, promenades, domes, mosques and hospitals built in this period. Besides that, topic of the customs, traditions and beliefs in the period of the Marwani Kurds has been dealt with. Furthermore, there are descriptions about the foundation and cooperation, economy and commercial activities in the Marwanis.
\end{abstract}

Keywords: Marwani Kurds, culture, civilization, Tarīkh al-Mayyāfāriqīn, Ibn alAzraq al-Fariqi.

\section{DESTPÊK: ÎBNU'L-EZREQ EL-FARİQ̂̂ Û TARÎXU MEYYAFARIQÎN}

Navê wî Ehmedê kurê Yûsuf kurê Elî kurê Ezreq e (el-Xûlî û Baluken, 2014:22). Lê wekî Îbnu'l-Ezreq el-Fariqî tê nasîn. Li gor agahîya ku Îbnu'lEzreq bi xwe di Tarîxu Meyyafariqînê da dide ew di sala 1119an da li 
Meyyafariqînê $\hat{~}^{3}$ hatiye dinyayê (Fariqî, 2014:552). Derheqê dîroka mirina wî de tu çavkanîyan de agahî nehatina peydakirin.

Îbnu'l-Ezreq hîn di ciwanîya xwe da dest bi xebata di karê dewletê da kiriye (Awad, 1959:31). Di sala 1148an da karê serperiştîya weqfên derveyê bajarê Meyyafariqînê kiriye (Fariqî, 2014: 593).

Destxeta Tarîxu Meyyafariqînê di muzeya British a li Londonê da ye. Li heman Muzeyê du nusxeyên berhemê hene. Ya yekem di beşa destxeta Opb And Mss bi nimreya Or.5803an tomarkirî ye û ji 400 rûpelî pêk tê û tê da bûyerên heta sala 1176an hatine vegotin. Nusxeya duyem jî di heman cihî da bi nimreya Or.6310an tomarkirî ye. Ev nusxe jî ji 276 rûpelan pêk tê û tê da bûyerên heta sala 1164an hatine vegotin (el-Xûlî û Baluken, 2014:7,12). Li gor agahîyên ku di beşa pêşî ya Tarîxu Meyyafariqînê da derbas dibin Fariqî di sala 1176an ev berhem nivîsîye (Fariqî, 2014:102).

Îbnu'l-Ezreq di rêvebirîya karên dewletê yên girîng da cih girtiye û ji ber vê taybetîya wî tiştên ku di serdema xwe da nivîsîne wekî belgeyên fermî ku bi destên rayedarên dewletê hatine nivîsîn, tên hesibandin. Li ser vê yekê jî dikare bê gotin ku ev berhema wî wekî belgeyeke fermî ya dewletê ye û ji alîyê dîrokî ve pir girîng e (Awad, 1959:4).

Îbnu'l-Ezraq Derheqê gelek eşîr û xanedanên kurdan da agahî dane. "Ji nav van ên ku bi awayekî geleki berfireh û hema bêje sal bi sal Îbnu'l-Ezraq agahî Derheqê wan da daye Merwanî ne" (Mansız, 2015:120). Herwiha di vê berhemê da agahîyên çandî û siyasî yên serdemên kevin û bi taybetî jî yên sedsala XIIan ku Îbnu'l-Ezreq tê da jîyaye hene. Derheqê dewleta Emewî, Ebbasî û xelîfeyên wan û rayedarên dewleta wan da jî agahîyan dide. Li ser mîrnişîn û dewletên wekî Selçûqî, Merwanî, Atabeg û Artûqîyan ku li Şam, Iraq, Cezîre, Ermenistan û Îranê hatine damezirandin disekine. Têkilîyên van dewletan ên bi hev ra û yên bi Endulus, Fatîmî û Bîzansîyan ra tîne zîmên (Awad, 1959:1-2).

Mijarên pirtûkê di bin van beşan da kom dibin: Beşa yekem behsa xîlafeta Emerê kurê Xetab (Fariqî, 2014:83-215 ), beşa duyem behsa rêvebirîya Muawîye (Fariqî, 2014:217-330), beşa sêyêm behsa destpêka xîlafeta Benî Ebbas (Fariqî, 2014:337-415), beşa çarem behsa destpêka rêvebirîya Hemdanîyan (Fariqî, 2014: ), beşa pêncem behsa destpêka rêvebirîya kurdan li Meyyafariqînê (Fariqî, 2014:449-705) û beşa şeşem behsa rêveberîya Necmeddîn Xazî û bidestxistina wî ya Meyyafariqînê (Fariqî, 2014:663-695) kiriye. Ji xeynî van agahîyên dîrokî, Îbnu'l-Ezreq di berhema xwe da behsa mijarên çand û şaristanîyê jî kiriye û di vî warî da agahîyên berfireh dane.

Heta niha li ser Tarîxu Meyyafariqînê hin xebat hatine kirin. Xebata pêşî ya li ser vê pirtûkê ku tê zanîn a Henry Frederîk Amdroz e. Piştra Vladimir Mînorsky ${ }^{3}$ Bajarekî di navbera herêma Cezîre û Ermenîyanê de ye. Hin kes wê ji herêma Ermenîyan û hin ji
cezîreyê dihesibînin. Dikeve rojhilatê Dîjleyê. Ji Amedê pênc fersaxan dûr e. (Bnr. Hîmyerî, 1984:567). 
li serê xebitîye. Piştî van rojhilatnasan Bedewî Evdilletîf Awad beşa Merwanîyan weşandiye û Mehmet Emîn Bozarslan ev xebata Awad wergerandiye tirkî. Piştî Bozarslan, Ahmet Savran jî beşa ku Derheqê Artûqîyan da ye wergerandiye tirkî. Lê cara pêşi ev pirtûk bi temamî ji hêla Karim Farouk û Yusuf Baluken ve hatiye weşandin. Di vî warî da teblîxeke Ali Sevîm jî di Kongreya Dîroka Tirkan a VI da li ser weşana Tarîxu Meyyafariqînê ya ku ji hêla Awad ve hatiye weşandin da heye (Sevim, 1967).

\section{RÊVEBIRÎYA DEWLETÊ}

\subsection{Mîr}

Li gor agahîyên ku Fariqî dide mîrê kurdan ê ku bingeha revebirîya Merwanîyan danîye Badê kurê Dostik e (Fariqî, 2014:450). Piştî mirina Bad, xwarzîyê wi yê mezin Ebû Elî Hesen rêvebirîya dewletê xistiye destê xwe (Fariqî, 2014:450). Lê bi serdema Ebû Elî ra di dewleta Merwanîyan da piştî mirina mîr, an birayê wî yan jî kurê wî li ser textê mîrîtîyê rûdinişt. Li gor agahîyên Îbnu'l-Ezreq piştî Ebû Elî, birayê wî Mumehîdduwle Ebû Mensûr bû mîr (Fariqî, 2014:461). Jixwe kurekî Ebû Elî tenê li pey mabû û ew jî dema Ebû Elî hatibû kuştin hêja piçûk bû (Fariqî, 2014:462). Piştî Mumehîduddewle birayê wî Nesruddewle Ehmed û piştî Nesruddewle Ehmed jî dîsa kurê wî Nîzameddîn bû Mîrê Merwanîyan (Fariqî, 2014:505). Mîrê Merwanîyan ê dawî jî kurê Mîr Nizameddîn, Nasiruddewle Mensûr bû (Fariqî, 2014:516).

Di dewleta Merwanîyan da mîr ji hêla desthilatdarîyê ve di rêza yekem da bû. Di karên rêvebirîya dewletê yên wekî îlana şer, gîrêdana peymanan, tayînkirina walîyan da mîran bîryar dida (Yûsuf, 2001: 75). Piştî mirina mîrekî, wezîrî mîre nû îlan dikir (Fariqî, 2014:450). Di berhema Îbnu'l-Ezreq da rêvebir û hikumdarê dewletê wekî emîr hatiye binavkirin. (Fariqî, 2014:453).

Nasnavên mîrên Merwanîyan hebûn. Li gor agahîyên Îbnu'l-Ezrak ji mîrên Merwanîyan cara yekem Ebû Mansûr nasnavê Mûmehîdudewle standibû. Ev nasnav jî wezîrê wî Mem lê kiribû (Fariqî, 2014:461). Nasnavê Ebû Nasir Ehmed jî Nesruddewle bû (Fariqî, 2014:474). Li gor Îbnu'l-Ezreq xizmetkarekî xelîfeyê Bexdayê Qadir Billah hin diyarî li ser navê xelîfe û siltan ji Ebû Nasir re şandin û wî jî nasnavê Nesruddewle dayê. Di heman demê da xelîfeyê Misrê Hakîm Bîemrîllah jî gelek diyarî ji Nesruddewle ra şandin û nasnavê Îzûdewle dayê (Fariqî, 2014:476).

\subsection{Wezîr}

Di dewleta Merwanîyan da gelek peywirên weziran hebûn. Tayînkirina walî û karmendên dewletê û betalkirina wezîfeya wan, dayîna meaşê karmendan, azadkirina kesên di girtîgehê da, destdanîna ser mal, îdarekirina leşkeran û beytulmalê hin ji wan peywiran bûn. Lêbelê wezîr bêyî şêwra mîr nikaribû bîryara kirina van karan bidina (Yûsuf, 2001: 78). 
Di dema Ebû Elî da jî wezir Mem bû (Fariqî, 2014:450). Piştî ku Mem û kurê wî Şêro, Ebû Elî kuşt, Mumehîduddewle Ebû Nasir bû mîr. Karûberên dewletê bi temamî ketin destê Mem û Şêro (Fariqî, 2014:452) û piştî Mem, Şero bû wezîr û alikarê Mumehîduddewle (Fariqî, 2014:466). Di rêvebirîya Merwanîyan da gelek caran mîr karûberên rêvebirîya dewletê dixist destê wezîran. Lê heta ku wezîr bi mîr neşêwirîyabûna bîryar nedidan (Fariqî, 2014:473).

Piştî ku mîr dimir wezîran karûberên dewletê dimeşandin. Fariqî bûyerên piştî mirina Nesruddewle wiha tîne ziman: "Dema Nesruddewle mir, wezîr, serokê artêşê şand mala Mîr Nîzameddîn û gazî wî kir. Pêşî wezîr, wekî mîr silav li Nîzameddîn kir û piştra zarok û pismamên wî, qazî, kesên alim û zana û giregirên bajêr hatin cemê û wan jî wekî mîr silav dan Nîzameddîn û herwiha gel jî li wir amade bû" (Fariqî, 2014:505). Piştî mirina Mîr Nîzameddîn jî dîsa Wezîr Ebû Tahir Selameyê kurê Enbarî rêvebirîya dewletê xist bin kontrola xwe û çû gazî Nesruddewle Ebû'l-Muzafer Mansûr kir (Fariqî, 2014:516).

Ji agahîyên ku Fariqî dide tê famkirin ku di Mîrnişîna Merwanîyan da kesekî ne misilman jî dikarîbû bibûna wezîr. Lewra wezîrê Nasiruddewle Mensûr, Ebû Salim kesekî fileh bû. Wexta Nasiruddewle Mensûr derket derveyê Meyyafariqînê rêvebirîya welat hemû xistibû destê wî û hevsera wî (Fariqî, 2014:518).

\subsection{Walî}

Mîrên Merwanîyan li Meyyafariqînê diman û ew bajarên din bi destê walîyan dihatin îdarekirin. Walîyên li bajarên Merwanîyan pere li ser navê mîr derdixistin û xutbe jî li ser navê wî didan xwendin. Agahîyên kesên ku di serdema Merwanîyan da walîtî kirine di pirtûka Fariqî da wiha derbas dibin: "Di serdema Mumehîduddewle da rêvebirîya Amedê ket destê Evdulber. Mumehîduddewle bi şertê ku salê du sed hezar dirhemî bidiyê, sikeyan li ser navê wî derxe û xutbeyan jî li ser navê wî bide xwendin rêvebirîya Evdulber a Amedê pejirand.” (Fariqî, 2014:463). Piştî ku Îbnî Dimne Evdulber kuşt û ket cihê wî nameyek ji Mumehîduddewle ra şand û xwest ku wî wekî walîyê Amedê bipejirîne. Piştî qebûlkirina mîr Îbnî Dimne bû walîyê Amedê (Fariqî, 2014:464).

Di serdema Ebû Elî û Mumehîduddewle da jî Xoce Ebû'l-Qasim walîtîya Erzenê dikir (Fariqî, 2014:469). Piştî ku Nesruddewle Amed ji Îbnî Dimne stand kurê xwe Ebû'l-Hesen kir walîyê Amedê (Fariqî, 2014:484).

\subsection{Karên Dîwan û Nivîsvanîyê}

Di serdema Merwanîyan da di rêvebirîya dewletê da ji xeynî wezîr û walîyan di qesrê da kesên ku karê dîwan û nivîsvanîyê dikirin jî hebûn. Hem di têkilîyên navxweyî û hem jî di yên derveyî da rola van kesan hebû. Agahîyên derheqê karê dîwan û nivîsvanîyê da di berhema Fariqî da wiha derbas dibin: "Piştî ku 
Nesruddewle kurê xwe ji bo walîtîyê danî Amedê û katibekî bi navê Îbnî Xemmar jî danî cemê" (Fariqî, 2014:484).

Di dema Nesruddewle da li ser navê wezîr, Îbnu'l-Bereke karê dîwanê dimeşand. Karê nivîsîna nameyan û nivîsvanîyê jî Şêx Ebû Nasir Menazî dikir Ebû Nasir ji Melazgirdê bû, helbestvanekî jêhatî bû. Çend caran bi qasidtî çûbû Qonstantînîyeyê cem qralê Romê. (Fariqî, 2014:486).

Lê ji agahîyên Îbnu'l-Ezreq tê famkirin ku nivîsvanê taybet ê artêşê bi xwe jî hebû. Lewra rojekê di navbera nivîsvanê Artêşê Ebû Hekîm û xulamekî mîr da gengeşî derdikeve. Ebû Hekîm serê xulam dişkîne û li ser vê xulam diçe li cem Nesruddewle gilîyê wî dike. Nesruddewle gazî Ebû Hekîm dike, lê Ebû Hekîm diçe xwe davêje mala kurapekî Nesruddewle yê bi navê Mîrzebanê kurê Belaşo (Fariqî, 2014:493).

\section{PERGALA HIQÛQÊ}

\subsection{Qazîtî û Darizandin}

Di dewleta Merwanîyan da qazîyan karê darizandinê dimêşand û ev qazî alîyê mîr ve dihatin tayînkirin (Ripper, 2012:513 ). Dema qazîyekî nû dest bi peywira xwe dikir fermannameya Derheqê tayîna wî da di xutbeyê da dihat xwendin (Fariqî, 2014:504). Qazîyê ku cara yekem Îbnu'l-Ezreq qala wî dike Elîyê kurê Ehmed e û di sala 998an da li Meyyafariqînê miriye. Piştî wî Hesenê kurê Munzir ku li cem serokê qazîên Bexdayê xwendibû hat, bû qaziyê Meyyafariqînê û heta sala 1010an qazîtîya vê derê kir. Piştî wî Ehmedê kurê Hamid bû qazîyê vê derê û sala 1020an qazîtîya vê derê kir (Fariqî, 2014:462).

Qazî Ebû Elî Hesenê Amedî jî, ku wekî Îbnî Bexel dihat naskirin, bû qazîyê Amedê. Îbnî Bexel yek ji giregirên Amedê bû. Mirovekî dewlemend bû. Qedr û qîmeta wî li cem Nesruddewle pir bû û li cem rêvebirê dewletê jî cihekî wî yê taybet hebû (Fariqî, 2014:491-492).

Di sala 1019an da Qazî Ebû Abdullah Huseyinê kurê Seleme jî bû qazîyê Meyyafariqînê û demekê wî û Şêx Ebû Mihemedê kurê Mîxfer qazîtîya wir bi hev ra meşand. Piştra Ebû Abdullah Huseyinê kurê Seleme bû qazîyê Amedê. Ebû Abdullah qazîtîya Meyyafariqîn û Amedê bi hev ra dimeşand (Fariqî, 2014:479). Qazî mehekê li Meyyafariqînê û mehekê jî li Amedê dima. Çardehê mehê digel maiyeta xwe sazbendên xwe û temamê pêdivîyên xwe ji Meyyafariqînê derdiket, her wiha kesên ku li karê qazîtî û darizandina Amedê jî dinêrtin bi vî awayî heman rojê derdiketin û ber bi wan ve dihatin. Her du alî li navbera Meyyafariqîn û Amedê, li Qasimiyê hev didîtin. Wê şevê li wir diman û roja din kesên ku ji Meyyafariqînê bi qazî ra hatibûn dîsa vedigerîyan Meyyafariqînê û Huseyinê kurê Seleme jî bi kesên ku ji Amedê hatibûn ra diçû Amedê û mehekê li wir dima. Meha din jî bi vî awayî qazî dîsa diçû Meyyafariqînê (Fariqî, 2014:484). 
Piştî mirina Ebû Abdullah Huseyinê kurê Seleme, Ebû Murca bû qazîyê Meyyafariqînê. Li gor Fariqî, Ebû Murca hiqûqnasekî hêja û baş bû. Lêbelê Ebû Murca hat kuştin û jîyana wî bi awayekî hovanê bi dawî bû. Îbnu'l-Ezreq derheqê kuştina wî da van agahîyan dide: "Rojekê nivîsvanê Ebû Murca li ser navê Qazî nameyek ji hevalekî xwe ra şand Mûsilê û çend pirtûkên fiqhê ku li Meyyafariqînê peyda nedibûn, jê xwestin. Dema mîr bi vê nameyê hesîya gazî qazî kir û ev name jê pirsî, lê qazî got: 'Haya min jê tune ye'. Nivîsvanê qazî rastîya meseleyê got, lê kesî jê bawer nekir û Qazî Ebû Murca hat kuştin. Piştî kuştina Ebû Murca di sala 1045an da Ebû Mensûrê kurê Şazanê Tûsî bû qazî. Tûsî mirovekî zana û hiqûqnas bû (Fariqî, 2014:498). Lê bi teşebûsa Îbnî Cehîr, qazîtî ji Ebû Mensûr hat standin û qazîyê Amedê Ebû'l-Qasim bû qazîyê Meyyafariqînê. Lewra bavê Ebûl-Qasim, Ebû Elîyê kurê Bexel qazîyê Amedê bû û wî qencî bi Fexruddewle kiribû û ew anîbû li welatê Merwanîyan kiribû walî. Paşê Nesruddewle, Qazîyê Amedê Ebû Elî Bexel avêt girtîgehê û dest danî serê qismekî ji malê wî" (Fariqî, 2014:504).

Li welatê Merwanîyan piştî sala 1076an peywira qazîtîyê bi destê lijneyekê hat meşandin. Di nav vê lijneyê da Îbnî Amir, Îbnî Zeydan û zarokên Qazî Elîyê kurê Bexel hebûn (Fariqî, 2014:515).

\subsection{Qanun û Cezakirin}

Îbnu'l-Ezreq behsa cezakirina Qazî Îbnî Mûrca dike. Li gor agahîyên wî Ebû Murca dixin bircekê û derîyê bircê li serê diseyînin û heta ku dimire di nava vê bircê de dimîne (Fariqî, 2014:498).

Dema ku di sala 1109an da Meyyafariqîn ket destê Sokmanê mîrê Xelatê li wir avahîyeke îşkenceyê hebû û ev der ji bo lêdanê dihat bikaranîn. Piştra bi fermana Sokman ev der hat xerabkirin (Fariqî, 2014:491-492). Lê ev avahî kengî hatiye çêkirin û ji kengî ve hatiye bikaranîn nayê nizanin, lewra Farîqî derheqê wê da tu agahîyên din nedane.

\section{ZANIST Û HUNER}

\subsection{Zanyarî û Teknîk}

Gelek alim û zana li welatê Merwanîyan hebûn. Yek ji van jî Ebûbekirê kurê Sedeqe bû. Li gor Îbnu'l-Ezreq, dema siltan ji bo walîtîya welatê Merwanîyan bidiyê gazî Amîduddewle kir Ebûbekirê kurê Sedeqe jî pê ra çû Esfehanê. Li gor neqla Îbnu'l-Ezreq ev kes alîmekî mezin bû. Lewra li medreseyên Esfehanê bi alimekî bi navê Muşta ra ketibû minazereyê û navê wî li her derê belav bûbû (Fariqî, 2014:527).

Kesekî din jî yê ku bi ilm û zanîna xwe derdikeve pêş Ebu'l-Qasim e. Ebû'lQasim Huseyinê kurê Elîyê Mexribî yek ji wezîrê Nesruddewle ye (Fariqî, 2014:485). Li gor Îbnî Xelikan Ebû'l-Qasim xwedî dîwan e û gelek berhemên wî yên navdar hene (Îbnî Xelikan, 1978:177). 
Di dewleta Merwanîyan da girîngî bi pirtûkan, komkirina wan û avakirina pirtûkxaneyan dihat dayîn. Di berhema Îbnu'l-Ezreq de derheqê sazkirina pirtûkxaneyên serbixwe de agahî tunin. Lêbelê li gor agahîya ku Îbnu'l-Ezreq dide di dema Nesruddewle da hin xebatên komkirina pirtûkan hatine kirin. Îbnu'l-Ezreq vê agahîyê wiha dide: "Şêx Ebû Nesr Menazî ku karê nivîsvanîya dewletê dimeşand gelek pirtûk kom kirin û ji van pirtûkan hin li Meyyafariqînê hiştin hin jî birin Amedê. Ev pirtûk li her du bajaran di mizgeftekê da bi cih kirin ku ev pirtûk hêja dimînin û wekî pirtûkên Menazî tên zanîn" (Fariqî, 2014:486).

Hin agahîyên Derheqê çêkirina alavên teknîkî da di berhema Îbnu'l-Ezreq da wiha derbas dibin: "Di nava seyrangeha Nesriyeyê ya ku Nesruddewle ava kiribû da bi saya dolabekê av ji çem dihat kişandin û bi vê avê baxçe dihatin avdan û hewz dihatin dagirtin" (Fariqî, 2014:489). Nesruddewle di mizgefta Meyyafariqînê da bi pereyên xwe yên şexsî binqamek ${ }^{5}$ çêkiribû (Fariqî, 2014:491). Bi saya vê binqamê gengeşiya di nav gel de ya ji bo avê çareser bûbû (Beysanoğlu,1996:1999).

\subsection{Helbest}

Ji gotinên Îbnu'l-Ezreq tê famkirin ku mîrên Merwanîyan, bi taybetî jî Nesruddewle, gelek qîmet daye helbestvanan. Helbestvan Tihamî hatiye cem Nesrûdewle û di helbestên xwe de pesnê wî û wezîrê wî daye. Helbestvanên bi navê Qaîd Ebû'r-Ridyê kurê Zerif ${ }^{6}$, Îbnî Sewdawî û Îbnî el-Xedirî jî hatine û ketine xizmeta Mîr Nesruddewle. Wekî din jî helbestvanên gelek welatan di gelek helbestên xwe da pesnê Nesruddewle dane. Helbestvan Sarî Dela di gelek helbestên xwe da pesnê Nesruddewle daye (Fariqî, 2014:490).

Dema mîrek dimir helbestvan li wir amade dibûn û zêmar li ser mîr dixwendin. Dema Mîr Nesruddewle û Mîr Nîzameddîn mirin, berî ku wan defin bikin helbestvanan li ser wan zêmar xwendin (Fariqî, 2014:505,517).

Di dema Nesruddewle da helbestvanekî Melazgirdî bi navê Şêx Ebû Nasir ku Îbnu'l-Ezreq pir pesnê wî dide û dibêje mirovekî baş û helbestvanekî jêhatî ye, karê nivîsvanîyê dimeşîne (Fariqî, 2014:498). Li gor agahîyên ku Îbnu'l-Ezreq dide nivîsvanê Qazî Ebû'l-Murca Ebûbekir jî helbesetvanekî bi navê Îbnu'lFatirî bû (Fariqî, 2014:498). Ev agahî nîşan didin ku mîrên Merwanîyan qedr û qîmet dane helbestvanan.

\footnotetext{
${ }^{4}$ Li gor Bozarslan ji ber ku ji Melazgirdê ye ev nav lê hatiye kirin (Bozarslan, 1990:134)

${ }^{5}$ Der heqê binqamê de di Burhan-i Qati de ev agahî hene: Binqam peyveke farisî ye. Bi gelemperî ji bo tasik an jî qedehê tê bikaranîn. Cûreyekî tasê ye ku bêtir li cem gundîyên Hindê tê naskirin. Berê bi vê tasê av dihat parvekirin. Binê qul bû û dema dora yekî dihat ji bo ku rez û bexçeyê xwe av bide diavêt nav avê û heta tasik tije dibû dor ya wî kesî bû (Beysanoğlu, 1996:1999).

${ }^{6}$ Di eslê berhemê de wekî "Terîf" derbas dibe. Navê wî ebû Reda Fedlê bîn Mensûr el-Fariqî ye. Di sala 1039an de miriye. Ew dîwana wî heye (Fariqî, 2014:505; el-Xûlî û Baluken, 2014:490).
} 
Rojên cejnan li pêşberî mîr digel rêvebirên dewletê û kesên ku ji dewletên din dihatin helbestvan jî amade dibûn. Roja cejnê ya sêyan qasidê xelîfeyê Bexdayê û yê Romê dema hatin cem Nesruddewle helbestvan jî li wir amade bûn (Fariqî, 2014:476).

Wexta welatê Merwanîyan ketibû destê walîyên Selçûqîyan, demekê ev welat bê walî mabû. Gelek giregirên bajêr xwestibûn ku dîsa walîyekî Selçûqî bê û vî welatê bi rê ve bibe. Lêbelê helbestvanekî bi navê Îbnî Esed hin xwendeker û dikandar li xwe civandin û wan welat parast û Meyyafariqîn radestî Nasiruddewle Mensûr kir (Fariqî, 2014:529-530). Ev helbestvan rojekê li Heranê çû cem siltanê Selçûqî jê ra helbestek xwend. Lê dema ji siltan ra hat gotin ku ev helbestvan ew kesê ku gazî mîrê Merwanî kir û Meyyafariqîn radestî wî kir. Îbnî Esed bi fermana siltan tê kuştin (Fariqî, 2014:531).

\section{ARTÊŞ Û EWLEHÎ}

\subsection{Artêş}

Di dewleta Merwanîyan da artêşeke birêkûpêk ku her tim amade hebû û pêdiviya vê artêşê ji alîyê dewletê ve dihatin dabînkirin. Ji xeynî vê artêşê şervanên ku bi dildarî ji bo welat şer dikirin jî hebûn (Yûsuf, 2001:125). "Bingeha artêşa Merwanîyan ji eşîreta Humeydî û Beşnewîyan ${ }^{7}$ pêk dihat (Lazarev û yên din, 2010:63).

Li gor agahîyên ku Fariqî dide artêşa Merwanîyan di bin fermana fermandarekî giştî da bû. Lewra dema Nesruddewle mir wezîr serokê artêşê şand mala Mîr Nîzameddîn û gazî wî kir (Fariqî, 2014:505). Herwiha em dizanin ku Îbnî Felyusê xulamê Şêro jî berpirsîyarê karê asayîşê bû (Fariqî, 2014:466).

Artêşa Merwanîyan ji kurdan û wan gelên din ên wekî ereb, suryanî, ermen, turkmen û gurcîyan pêk dihat (Yûsuf, 2001:127). Di dema Mumehîduddewle da xanedanekî gurcî ji ber qralê gurcî revîyabû û digel girseya pê ra hatibû ketibû bin xizmeta mîrê Merwanî (Fariqî, 2014:471). Leşkerên gurcî yên di artêşa Merwanîyan da cih digirtin ev kes bûn.

Em ji agahîyên Îbnu'l-Ezreq fam dikin ku hin cihên weqifkirî ji leşkeran ra hatibû veqetandin. Lewra bazirganekî bi navê Îbnu'l-Behat gundekî bi navê Benînûh kiriye û ji bo leşkeran weqif kiriye (Fariqî, 2014:500).

\section{2. Çek}

Em ji berhema Îbnu'l-Ezreq fam dikin ku di dewleta Merwanîyan gurz û tîr wekî çekekê hatine bikaranîn. Lewra Ebû Tahir Yusuf Îbnî

${ }^{7}$ Her çiqas di nav pirtûka Lazarev de navê van eşiran Humaydî û Başnawî hatibe nivîsandin jî li gor telafûza rastî navê van eşîran Humeydî û Beşnewî/Becnewî, ye. Li heremê li gor devokên di nav Kurdan de tê bi karanîn elbet guherto û versîyonên din hebin jî ev yek normal tê qebûl kirin. Me li vir kar anîna devoka Kurd hilbijart. 
Dimne bi gurzê li serê Mîr Ebû dixe û wî dikuje (Fariqî, 2014:452). Herwiha leşkerên dewleta Merwanî tîr bi kar anîne heta di nav leşkerê Merwanî da komek tîravêjên gurcî hene. Ev tîravêj ji gurcîyan pêk tên û di dema desthilatdarîya Şêro ya Meyyafariqînê da bi fermana Îbnî Felyûsê kurê Şêro ev leşkerên gurcî bi tîrên xwe gelek kesan dikujin (Fariqî, 2014:471).

\section{AVAHÎSAZî Û̉ BAJARVANî}

\subsection{Sûr}

Sûrên Meyyafariqînê di serdema gelek dewletan da li ser piyan mane. Di dema Merwanîyan da jî gelek cihên sûran ji nû ve hatine çêkirin. Birayê Bad Ebû Fewaris, Ebû Mensûr Mumehîduddewle, Ebû Elî cihên xerabe yên sûran restore kirine û navê xwe li ser van sûran nivîsîne. Nesruddewle û Nîzameddîn jî gelek sûr û birc dane çêkirin. Bi vî awayî sûrên Meyyafariqînê tamîreke baş dîtine (Fariqî, 2014:498).

Îbnu'l-Ezreq dide zanîn ku cara pêşî birayê Bad Ebû Fewaris di nava du salan da cihên xerabe yên sûrên Meyyafariqînê çêkirin û herwiha navê wî li ser çend cihên sûran hatiye nivîsîn (Fariqî, 2014:450). Piştî ku Amed ketiye destê Îbnî Dimne wî jî sûr qamekê bilindtir kirine. Ew cihê ku Îbnî Dimne çêkirine hêjî diyar e (Fariqî, 2014:464).

Mumehîduddewle gelek deverên sûrên Meyyafariqînê çêkirin. Ji alîyê hindir ve li bîst û du cihan û li gelek deverên hindir jî navê wî nivîsandiye. Sih û tiştek deverên sûrên wê çêkirine. Dîsa birca ber derîyê navîn xerab bûbû Mumehîduddewle ev der çêkiriye. Derîyê Qulfayê ku di navbera du bircan da ye jî Mumehîduddewle vekiriye (Fariqî, 2014:466). Îbnu'l-Ezreq dibêje ku ji alîyê hindirê sûran ve neh dever û ji derve ve jî sih û tiştek dever ji alîyê Nesruddewle ve hatine çêkirin û Fariqî dibêje "min bi xwe ev jimartine". Herwiha bi taybetî ji bo mesrefa çêkirina sûran weqif hatibûn çêkirin. Lewra Nesruddewle ji bo sûran gelek gund û cihên din weqif kiribûn. Mesela Hemama Eqabe û Hemama Nû ku li deşta Şûrçanê hatibû çêkirin ji bo sûran hatibûn weqifkirin (Fariqî, 2014:498).

Wextê Îbnu'l-Ezreq qala serdema Mîr Nîzameddîn dike dibêje di dewra Mîr Nîzameddîn da gelek karên avahîsazîyê li Meyyafariqînê hatin kirin. Mîr Nîzameddîn gelek deverên sûrên Meyyafariqîn û Amedê bilind kirin. Li ser van deveran hem ji alîyê hindir û hem jî ji alîyê derve navê wî hatiye nivîsîn (Fariqî, 2014:516). 


\subsection{Birc}

Li gor agahîyên ku Fariqî dide di sala 1070yî da Mîr ${ }^{8}$ Nîzameddîn tebeqeya çaran avêt ser birca mîr a li Meyyafariqînê. Berpirsîyarê çêkirina vê bircê Qazî Ebû Nesr Hîbetullahê kurê Şazî bû û mesrefa wê jî siltan ji kîsê xwe da. Di serdema Mîr Nîzameddîn da li ser derîyê hindirê bajêr du birc hatin çêkirin li ser van bircan dûrbîn û eynik hene. Ev birc di bin berpirsîyarîya Ebû'l-Hesen Ehmedê kurê Bexel da hatin çêkirin û li ser wan navê wî hatiye nivîsîn (Fariqî, 2014:515).

\subsection{Keleh}

Fariqî di berhema xwe da behsa çêkirina kelehekê dike. Ev agahî di Tarîxu Meyyafariqînê da wiha derbas dibe: "Nesruddewle kelehek di navbera sînorê xwe û Senasînayê da bi pereyê xwe yê şexsî ava kir. Ev bû bend û sînor û welatê Merwanîyan li dijî Senasînayê parast.” (Fariqî, 2014:500).

\subsection{Qesr}

Piştî ku rêvebirîya Amedê ket destê Îbnî Dimne wî li rojhilatê bajêr li alîyê çemê Dîjleyê qesrek ava kir. Li alîyê çem derîyekî vê qesrê vekir û navê vir kir Derîyê Avê. ${ }^{9}$ Piştî ku Nesruddewle Meyyafariqîn ji Şêro stand û xist bin desthilatdarîya xwe di sala 1013yan da li rex birca hikûmdarîyê qesrek çêkir. Pereyekî pir li vê qesrê xerc kir û qesreke gelek sipehî ava kir. Dîwar û qarçikê wê bi nexşê zêrîn xemilandin (Fariqî, 2014:476).

\subsection{Pir}

Merwanîyan bacên ku piranîya wan ji karê bazirganîyê bi dest dixistin ji bo çêkirina rêyan xerc dikirin (Ripper, 2012:468 ). Li gor agahîyên ku Fariqî dide Nesrûdewle li ser Çemê Hewê pirek da çêkirin. Bûyera çêkirina vê pirê di berhema wî da wiha derbas dibe: "Di serdema Mîr Ebû Elî da dema Ebû Elî ji Meyyafariqînê ber bi Amedê ve diçû Nesruddewleyê birayê Ebû Elî jî pê ra bû. Piştî ku baran barî û çemê Hewê rabû wan nikaribû derbasî alîyê din bibin. Ancax roja din bi zorê di nav av û herîyê da derbasî alîyê din bûn. Hêja di wê rojê da Nesruddewle ji xwe ra gotibû: 'Eger rojekê Xweda mîrîtîyê bike nesîbê min ji bo ku gel di ser ra derbas bibe ez ê pirekê li vir çêbikim' (Fariqî, 2014:461). Piştî ku Îbnû'l-Bexl bû qazîyê Amedê Nesruddewle jê xwest ku pirekê li ser çemê Hewê çêbike û di sala 1040î da li vir pirek hat çêkirin. Navê kurê mezin ê Mîr Nesruddewle û mirovekî ji gelê Amedê bi navê Îbnî Uqeylî û agahîyên derheqê qazîtîya Ebû Elî da li ser vê pirê hatin nivîsîn (Fariqî,

${ }^{8}$ Di eslê metnê de siltan hatiye nivîsîn. Mimkun e ji ber ku berê Nîzamilmilk bernavkê "Siltanê Mîran" dabû Mîr Nîzameddîn ev peyv hatibe bikaranîn (Fariqî, 2014:505; el-Xûlî û Baluken, 2014:515).

9 Dibe ku ev ew derîyê ku niha wekî "Yeni Kapi/Derîyê Nû" tê binavkirin be (Bozarlan, 1990:95). 
2014:492). Li gor agahîyên ku Beysanoğlu dide ev pira ku Îbnu'l-Ezreq qala wê dike li ser rêya Farqîn û Diyarbekirê ye bi 12 kîlometran dûrî bajêr e û li ser çemê Enbarê ye. Ev pir piştra xerab bûye û di sala 1223yan da bi awayekî xweşik hatiye tamîrkirin. Wisa xuya dike ku ev nivîsên li serê yên ku Îbnu'lEzreq qala wan dike hingê xerab bûne "(Beysanoğlu,1996:200). Pira din a ku di serdema Nesruddewle da çêbûye pira li seyrangeha wî ya Nesriyeyê ya li ber girê Benanê ye (Fariqî, 2014:489).

Mîr Nîzameddîn jî di sala 1080yî da li rojhilatê Amedê li ser Çemê Dîjleyê pirek çêkir. Temamê mesrefa vê pirê ji pereyên xwe yên şexsî dan û berpirsyarîya çêkirîna wê Wezîr Ebû'l-Fadl Îbrahîmê kurê Enbarî kir (Fariqî, 2014:516). Navê vê pirê di nav gel da wekî Pira Dehderî10 tê zanîn. Lê ev pir berê jî hebû. Di sala 974an da Ji hêla Împeretorê Bîzansê Juannes ve hatibû xerabkirin û Mîr Nîzameddîn ev der ji nû ve çêkir. Îbnu'l-Ezreq dîroka çêkirina wê wekî 1080ê daye (Fariqî, 2014:516) lê li gor Beysanoğlu ji nivîsa ser pirê tê famkirin ku ev pir di sala 1065an da çêbûye (Beysanoğlu,1996:221).

\subsection{Qenalên Avê}

Li gor agahîyên ku Fariqî dide di rêvebirîya Merwanîyan da qenalên avê carinan bi destê mîrekî (Fariqî, 2014:476) carinan bi pereyên weqfê û carinan jî bi piştgirîya kesên dewlemend dihatin çêkirin. Li gor Îbnu'l-Ezreq ji serêkanîyê ê $^{11}$ sê qenalên avê dihatin nava Meyyafariqînê (Fariqî, 2014:499).

Di sala 1013yan da piştî ku Nesruddewle qesreke nû li Meyyafariqînê ava kir ji serê kanîyê qenaleke avê kişand qesrê û li wir hemam û hewz çêkirin (Fariqî, 2014:476). Îbnî Şelîta, berpirsyarê weqfan, ji mal û tiştên weqfan gelek pere berhev kiribûn û bi wan pereyan ji serê kanîyê qenaleke avê kişand nava Meyyafariqînê. Gelek pere li vê qenalê xerc kirin û qenaleke pir zexm çêkir. Ev qenal di binê Mizgefta Serêkanîyê ra derbas dibû û ji alîyê rojhilat ve di nîvê Rabadê diçû û ji wir digihişt Derîyê Avê û binê birca mîr. Ji wir jî diçû digihişt derîyê bircek ji ya Derîyê Qulfayê û bi vî awayî av derbasî rojavayê bajêr dibû (Fariqî, 2014:499).

Di serdema Nesruddewle da bazirganekî bi navê Ebûbekir Mihemedê kurê Cerî hebû, wî jî qenaleke avê kişand nava Meyyafariqînê. Ebûbekir ji alîyê rojava ve qenal anî ber sûran û ji wir jî derbasî baxçeyê sûra biçûk kir. Heta ku gihand vir pêncî hezar dînar mesref lê kir. Piştra çû cem mîr ji bo ku sûrê qul bike jê destûr xwest, piştî mîr destûr dayê sûr qul kir û qenal bir nava her du sûran û ji wir jî bir serê kanîyê. Piştra ev qenal li nava bajêr gerand bir mizgeft û Bazargeha Qubê. Ebûbekir ev qenal di ber mala xwe ra derbas kir lê av jê nekişand mala xwe. Dema sedema vê jê pirsîn wiha got: "Weleh ez ji vê qenalê avê nakişînim

\footnotetext{
${ }^{10}$ Di pirtûka Behsanoğlu de der barê vê pirê de agahî hene. (Beysanoğlu,1996:221).

${ }^{11}$ Xuyaye ku Serêkanîyê kaniyeke bi navê kanîya mezin ku niha jî li bakurê bajêr dimîne ye (Beysanoğlu, 1996:221).
} 
mala xwe. Eger ez bikişînin dê bibêjin Ebûbekir, ev av ji bo mala xwe û feyda xwe anîye" (Fariqî, 2014:499-500).

\subsection{Seyrangeh}

Nesruddewle ji bo xwe, malbat û pismamên xwe seyrangeheke bi navê Nasiriyeyê li qiraxa çem ava kiribû. Di nava vê seyrangehê da jî qesreke xweşik, bazargeh û hemam çêkirin û ji bo her kurekî xwe û kurapekî xwe xanîyek tê da ava kiribû (Fariqî, 2014:489).

\subsection{Qub}

Li gor agahîya ku Îbnu'l-Ezreq dide piştî ku birayê Bad, Ebû'l-Fewaris hat kuştin li cihê ku hat binaxkirin qubek hat çêkirin û herwiha piştî vê li wir gelek qubên din hatin çêkirin û ji vir ra Qubên Ebû'l-Fewaris tê gotin (Fariqî, 2014:452).

\subsection{Mizgeft}

"Nesruddewle di sala 1024an da minareya mizgefta Rabadê çêkir (Fariqî, 2014:482). "Di cihê vê mizgefta ku Îbnu'l-Ezreq qala wê kiriye da îro tiştek nemaye" (Beysanoğlu,1996:196).

"Nesruddewle di sala 1033yan da Mizgefta Muhdeseyêe ${ }^{12}$ ava kir û temamê mesrefa vê mizgeftê ji pereyên xwe yên şexsî dan û herwiha hin weqif jî ji bo vê mizgeftê çêkirin (Fariqî, 2014:488).

\subsection{Nexweşxane}

Li gor agahîyên ku Fariqî dide Nesruddewle di 1024an da bi pereyên xwe yên şexsî nexweşxaneyek ava kir (Fariqî, 2014:531). Îro li cihê vê nexweşxaneyê tiştek nemaye (Beysanoğlu,1996:196).

\section{JÎYANA ABORÎ Û BAZIRGANÎYÊ}

\subsection{Aborî}

Berî desthilatdarîya Merwanîyan nêzî nîv sedsalî welatê Merwanîyan di bin deshilatîya Hemdanîyan da bû. Di vê serdemê da ev welat di warê çandinî, huner û aborîyê da bi pêş neketibû. Di serdema Merwanîyan da ev pêşketin pêk hat. Yûsif sedemên sereke yên vê pêşketinê bi îstîqrar û aşîtîya di nav welatê Merwanîyan ve girê dide û dibêje: "Ji sala 993yan heta dawîya 1026an ango sih û pênc salan û ji sala 1036an heta sala 1083yan ango 49 salan şer û pevçûn di navbera Merwanîyan û tu mîrnişîn û dewletan da çênebûn. Ev şert û merc bûn sedemên pêşketina pîşesazî, aborî, çandînî û bazirganîya welatê Merwanîyan (Yûsuf, 2001:177).

\footnotetext{
${ }^{12}$ Muhdese leşkergeheke li derveyê Meyyafariqînê bû. (Beysanoğlu,1996:198).
} 
Di serdema Mumehîduddewle da rewşa Merwanîyan a aborî pir ne baş bû. Bi taybetî ji ber xelaya ku di vê serdemê da didome bihayê tiştan gelek zêde bûye heta li gor neqla Îbnu'l-Ezreq di serdema Mumehîduddewle da ji ber xelayê bihayê elbek genim bûye deh zêr (Fariqî, 2014:469). Lê di serdema Nesruddewle bi taybet bi sedema meşandina siyaseteke biîstîqrar dewlet di warê aborî û bazirganîyê da gelekî bi pêş ketibû. Li gor Fariqî di serdema Nesrûddewle da di welat da aştî û aramî hebû û mîr bi gel ra bi edalet tevdigerîya. Di serdema wî da bajarê Meyyafariqînê bi pêş ketibû û ji her derê bazirgan û mirovên din dihatin vir (Fariqî, 2014:478).

Di warê vê pêşketina aborî da cudahî di navbera Meyyafariqîn û Amedê da hebû û vê rewşê gelê Amêdê aciz dikir. Wan dixwest têkilîya xwe ji Meyyafariqînê bibirin û xweser bibin (Ripper, 2012:294). Mîrov dikare vê bûyera ku Mîr Ebû Elî ji alîyê rêvebirên Amedê ve hat kuştin (Fariqî, 2014:461) û Amed bîst û heşt salan ji destê Merwanîyan derket bi vê rewşê ve girê bide (Fariqî, 2014:481).

Dema Îbnu'l-Ezreq behsa xweşî, îstiqrar û dadmendîya serdema Nesruddewle dike bûyereke musadereyê ${ }^{13}$ jî wiha neqil dike: "Di dewra Nesruddewle da zilm li kesî nehatibû kirin û ji xeynî Şêx Ebûbekirê kurê Cerî dewletê dest nedanî ser malê kesî. Sedema destdanîna li ser malê Şêx Ebûbekirê kurê Cerî ev bû: Şêx Ebûbekir dostê hikûmdarê Senasîna bû û ji mîr ra hat gotin ku Şêx Ebûbekir têkilî bi hikûmdar ra danîye û dixwaze bajêr radestî wî bike. Bi fermana Nesruddewle leşkeran avêt ser mala wî û gelek çek di mala wî da hatin girtin. Ji bo vê yekê rayedarên dewletê dest danîn ser mal û çekên wî. Bahayê mal û çekên wî ku dewletê dest danîbû serê, çar sed hezar dînar bûn. Ji ber ku rayedaran agahî şaş dabûne mîr û ev musadere pêk hat, hekena heta niha nehatibû dîtin ku Nesruddewle yek dirhemek jî ji kesekî sitendibû" (Fariqî, 2014:500-501). Di serdema Nesruddewle da gelek pere hatin xerckirin û di nav bexçeyê Reîs Elîyê kurê Mensûrê kurê Kek da kargehek hat avakirin (Fariqî, 2014:501).

\subsection{Bazirganî}

Cihê Merwanîyan ê stratejîk di warê bazirganîyê de hin avantaj bi xwe ra anîbûn. Meqdisî ku di dewra Merwanîyan da jîyaye ev taybetî wiha anîye ziman: "Welatê Merwanîyan wê demê di navbera Bîzansîyan û paytexta Ebasîyan da bû û di navbera Rojhilat û Asyaya Biçûk da wekî pirekê bû. Bajarê Amedê li ber qeraxa Dîjleyê bû û ev der navendeke aborîyê bû. Di ser vir ra tiştên welatê kurdan û welatê Rojhilat ên din diçûn Asyaya Biçûk. Di heman demê da jî ev der ji bo tiştên ku ji welatên Bîzansîyan tên wekî bazargehekê bû. Di sedsala X'an da malê ku ji Bîzansê dihat di ser Amedê ra diçû Bazargehên Bexdayê" (vgz.Yûsuf, 2001:47-48). Qumaşekî ku di sala 1940î da li Mîlanoyê derket holê û navê Nesruddewle li ser nivîsandî bû vê rastîyê nîşan dide (Ripper,

${ }^{13}$ Destdanîna ser tiştekî, jê stendin (Farqînî, 2013:850) 
2012:15 ). Bajarê Meyyafariqîn û Amedê li ser rêyên bazîrganî yên navneteweyî bûn û sedema sereke ya vê pêşketina aborî ev bû. Li gor neqla Gabriel, dema Ebû'l-Ala Maarrî ji Bexdayê vedigere welatê xwe yê li bakurê Surîyeyê digel ku dûrbûna wê jî, ji ber arambûn û ewlehîyê rêya Diyarbekirê tercîh dike (vgz. Ripper 2012:89).

Di welatê Merwanîyan da ji bo bazargehan cihekî taybet heye. Fariqî di berhema xwe da der barê bazargeha Meyyafariqînê û Amedê da gahîyan dide û wiha dibêje: Li Bazargeha Qumaşfiroşan bûbû eded ku kesekî nikaribû bi siwarî di navê ra derbas bibe. Rojekê kurapekî mîr ê nêzî wî di vir ra derbas bû. Kesên bazargehê bertek nîşanî wî dan û cihê ku hespê wî lewitandibû pê dan paqijkirin (Fariqî, 2014:456). Dîsa em ji gotinên Fariqî fam dikin ku li Amedê bazargeha zad û zexîreyan bi rêkûpêk dihatin îdarekirin. Serokekî vir hebû û ev kes ji girêgirên bajêr dihat hilbijartin. Di serdema Mîr Ebû Elî û Mumehîduddewle da serokê vê çarşîyê kesekî bi navê Evdulber bû (Fariqî, 2014:460). Wekî din navên sê bazargehên Meyyafariqînê jî di berehema Îbnu'l-Ezreq da derbas dibin. Yek jê Bazargeha Qumaşfiroşan, yek Bazargeha Qubê û ya din Bazargeha Etaran e ku dikana Hekîm Ebû Salim li vir bû (Fariqî, 2014:456,499,518).

Dema Îbnu'l-Ezreq qala xweşî û aramîya di serdema Nesruddewle da dike qala bazîrganekî bi navê Îbnu'l-Behat dike bê çawa di rojekê da pênc sed dînarên Armanosî ${ }^{14}$ kar kirine. Fariqî vê bûyerê wiha neqil dike: "Li Meyyafariqînê simsarekî bi navê Îbnul-Behat hebû. Rojekê karwanek hat bajêr û Îbnû'l-Behat hemû malê bi vî karwanî re kirî. Di heman rojê da karwanekî din hat û Îbnu'lBehat ev mal firote vî karwanî û ji vê bazara ku kirî pênc sed dînarên Armanos kar kirin. Li ser vê Mîr Nesruddewle gazî wî kir. Îbnu'l-Behat çû hizûra mîr û dema mîr rastîya vê bûyerê jê pirsî û Îbnu'l-Behat tişta ku mîr bihîstibû tesdîq kir û pere danîn ber mîr. Li ser vê mîr wiha got: 'Bi Xwedê min ne ji bo ku ez van pereyan ji te bistînim gazî te kir. Min xwest ez bizanim ka rast e ku mirovek li welatê min di rojekê da pênc sed dînarî kar dike.' Mîr sûnd xwar ku tiştekî ji van pereyan nebe û li ser vê Îbnu'l-Behat jî sûnd xwar ku van pereyan nexe nav malên xwe. Îbnu'l- Behat bi van pereyan gundekî li derdora Amedê kirî. Ev gund li ser keleha Fetrasa ya bi navê Benînûh e. Îbnu'l- Behat ji bo leşkerên ku li Akil ${ }^{15}$ û Yemanî û Cebarê diman ev der weqif kir (Fariqî, 2014:500).

\subsection{Bac}

Li welatê Merwanîyan baca hin tiştan dihat standin. Ev bac ya rez û bexçeyên li dora bajêr, ya mêwe, zebze, dexil, êzing û komirê bû (Fariqî, 2014:526). Ji xeynî van, baceya aşarê jî hebû. Lewra Îbnu'l-Ezreq dibêjê piştî ku siltanê Selçûqî hat Meyyafariqînê baca aşarê ji ser gel rakir (Fariqî, 2014:530). Em ji agahîyê Fariqî

\footnotetext{
${ }^{14}$ Agahîyên der heqê pereyên ku ji alîyê Bîzansîyan ve hatine derxistin di berhema di pirtûka Evdirreqîb Yûsuf de derbas dibin. (Yûsuf, 2001: 114).

15“Akil" bajar û keleheke kevin e û nezî Amedê ye niha navê wê "Eğil" e. (el-Xûlî û Baluken, 2014:500).
} 
tê digihîjin ku di serdema Merwanîyan da karê tehsîldarîyê jî heye, lewra Îbnu'lEzreq qala kesekî bi navê Mihemed Ebû'l-Hesen dike ku tehsildarê weqfan e (Fariqî, 2014:503).

\subsection{Pere}

Di dewleta Merwanîyan da dirhem û dînar dihatin bikaranîn. Di heman demê da bi taybetî jî li cihên ji bajaran dûr bi awayê pevguherandina tiştan bazar dihat kirin. Lêbelê qada bikaranîna dirheman bêtir berbelav bû. Dînarên zêr bêtir di bazirganî û di têkilîyên nav dewletê û derveyê dewletê da dihatin bikaranîn (Yûsuf, 2001:105). Mesela dema Ebû Elî keça Sadûddewleyê Hemdanî xwest du sed dirhem wekî next dan (Fariqî, 2014:459). Dema Melik Ezîzê Buweyhî hat cem mîrê Merwanî Nesruddewle bi awayekî xweşik ew pêşwazî kir û bîst hezar dînar danê (Fariqî, 2014:491).

Pereyên ku ji alîyê Merwanîyan ve hatine derxistin di mûzeya Brîtanyayê ya li Londonê da hene. Ehmed Etiye jî qala pereyên ku di serdema Ebû Elî da li Cizîrê di sala 995an da û di serdema Nesruddewle da li Xelatê di sala 1011an da hatine derxistin dike û dibêje: "Ji xeynî van deveran li Dineyser, Meyyafariqîn û Amedê jî pere dihatin derxistin" (Vgh. Yûsuf, 2001:112).

Gelek caran rêvebirên dewletê ji bo ku gel û leşkeran bikişînin alîyê xwe devê xezîneya dewletê vedikirin û mal û pere li leşkeran belav dikirin. Li gor neqla Fariqî dema Xoce Ebû'l-Qasim ji bo ku Mîr Ebû Nasir biçe rêvebirîya Meyyafariqînê ji Şêro bistîne û herwiha ji bo ku gel piştgirîya wî bike gelek mal û pere li wan belav kirin (Fariqî, 2014:470). Di heman demê da Şêro jî ji bo gelê Meyyafariqînê piştgirîya wî bikin mal li wan belav kir (Fariqî, 2014:471).

\section{BÎR Û BAWERî}

\subsection{Dîn û Mezheb}

Em ji gotinên Îbnu'l-Ezreq derdixin ku ji xeynî misilmanan di nava dewleta Merwanîyan da mensûbên dînên din jî hebûn û li hemberî wan siyaseteke baş dihat meşandin. Herwiha di rêvebirîya dewletê û karên din ên cûrbecûr da jî gelek kes ji mensûbên dînên din hebûn. Wezîrê Nasiruddewle Mensûr fileh bû. Ev wezîrê fileh Ebû Salim û hevsera wî Ferîhaya keça Filîstîn di qesra Nasiruddewle Mensûr da bûn û qîmeta wan pir bû û karûberên dewletê di destê wan da bûn (Fariqî, 2014:518). Di nav artêşa Merwanîyan da ji xeynî misilmanan leşkerên gurcî jî hebûn (Fariqî, 2014:503) û ji serdema Ebû Elî û vir ve karên Weqfan jî bi destê mirovekî fileh ê bi navê Îbnî Şelîta dihatin meşandin (Fariqî, 2014:499).

Ji gotinên Îbnu'l-Ezreq tê famkirin ku azadîya filehan a dînî piştî ku Meyyafariqîn ketiye destê Selçûqîyan ji holê rabûye. Bi taybetî jî di dema walîyê Selçûqî Ebû Elî Belxî da dengê naqosa filehan hatiye qedexekirin û dêra wan hatiye girtin û bûye mizgeft. Li gor agahîyên Fariqî, Fexruddewleyê ku li 
ser navê siltanê Selçûqî welatê Merwanîyan bi rê ve dibir di sala 1086an da hat Meyyafariqînê û dêra Ûbadê kir mizgeft. Piştra dîsa filehan pere dan û ev der dîsa kirin dêr. Amîdulmulk Ebû Elî Belhîyê ku siltan walîtîya welatê Merwanîyan dabûyê rojekê dema dengê naqosê bihîst, aciz bû û bi fermana wî ev dêr dîsa bû mizgeft (Fariqî, 2014:524).

Heta ku Selçûqî hatin vê herêmê Merwanîyan şêst salî li dijî Buweyhîyên şiî, filehên rom û ermenîyan berpirsyarîya mezhebê sunîtîyê dikir (Tufantoz, 2005:125). Di warê mezhebê emelî da jî mezhebê Merwanîyan ê fermî şafiîtî bû. Piştî ku Merwanîyan desthilatdarîya herêmê xist destê xwe mezhebê şafiîtîyê belav kir. Gelek alimê şafî̂ hatin li welatê Merwanîyan bi cih bûn (Baluken, 2010:35). Bi taybetî bi piştgirîya xelîfeyê Ebbasî, şafîitî li welatê Merwanîyan belav bû ( Biçer, 2014:122). Di serdema Nesruddewle da di sala 1045an da Ebû Mensûrê kurê Şazanê Tûsî bû qazîyê Meyyafariqînê û di heman demê da jî berpirsyarîya weqfan jî di destê wî da bû (Fariqî, 2014:498). Di serdema xwe da Tûsî alimekî mezin ê mezhebê şafiî bû (Baluken, 2010:36).

Lê di nav dewleta Merwanîyan da alimên neşafiî jî hebûn. Ebû Evdillah Huseyinê kurê Ehmedê kurê Seleme malikî bû (Baluken, 2010:42) û di serdema Nesruddewle da Mehekê li Amedê û mehekê li Meyyafariqînê dima û qazîtîya van herdu cihan bi hev ra dimeşand (Fariqî, 2014:479).

Di serdema Merwanîyan da li welatê wan mezhebê henîfî pir tuneye lê piştî ku Selçûqî hatin vê herêmê mezhebê henefî li vir belav bû. Bi taybetî jî di belavbûna mezhebê henîfî li vê herêmê da bandora mîrnişîna Artûqîyan pir e (Baluken, 2010:42).

\subsection{Stêrzanî û Bawerîyên Mîstik}

Mîrên Merwanîyan girîngî dane stêrzanan. Hin mîran stêrzan anîbûn cem xwe û gotinên van stêrzanan li cem mîr pir biqîmet bûn. Îbnu'l-Ezreq qala du stêrzanên di serdema Nesruddewle û Nizamedîn da dike û wiha dibêje: "Rojekê ji Hindê falbazekî zana hat cem Nesruddewle û mîr gelekî qîmet dayê û gelek qencî pê kir. Falbaz Derheqê paşeroja wî da ev tişt jê ra gotin: 'Mîre min mirovekî ku tu jê hez dikî, tu qîmet didiyê piştî mirina te dê mîrektîyê ji malbata te bistîne û malbata te ji holê rake. Lêbelê di demeke kurt da desthilatdarîya vî welatî dê ji destê wî jî derkeve.' Li ser vê, mîr hinekî fikirî û berê xwe da Fexruddewle û wiha got: 'Ku ev gotin rast be kesê ku vê bike ev kal e.' Dema Fexruddewle ev gotinên mîr bihîstin wiha got: 'Ezbenî ez li ku kirina vî karê ha li ku?' Lê piştra ev gotinên falbaz rast derketin (Fariqî, 2014:503). "Di serdema Mîr Nizamedîn da di sala 1071ê da stêrzanekî bi navê Îbnî Aysûn hatibû cem Mîr Nizamedîn. Ev stêrzan her wextî di civata Mîr Nizamedîn da amade bû. Şevekî Îbnî Aysûn û mîr bi hev ra li bajêr dinêrtin û sternas ji mîr ra wiha got: "Mîrê min ev çi bajarekî xweş e lê piştî te bi heştê salî zilm û zordestî dê li vir serdest bibe." Gel li hemberî van gatinan metel ma. Lêbelê gotinên vî stêrzanî rast derketin. Lewra piştî Merwanîyan welat ket destê tirkên Selçûqî û rêvebir guherîn. Zilm û 
zordestîyê dest pê kir û çawa ku stêrzan gotibû, gel feqîr û belengaz bû" (Fariqî,, 2014:517). Dema ku Mîr Nizamedîn mir jî vî stêrzanî li bircê stêran nêrt û got ku heta sê rojan Ebû'l-Mensûr nikare here ser textê mîrîtîye. Li ser vê, termê Mîr Nîzameddîn hat şûş̧in û kefenkirin û di nav darbestê da sê rojan hat sekinandin. Heta li gor ku tê gotin di vê navberê da mişkan her du çavên wî xwarine" (Fariqî, 2014:516). Ev agahî nîşanî me dide ku mîrê Merwanîyan û rêvebirên wan pir girîngî dane gotinên falbazan û li gor wan tevderîyane. Herwiha di nav gel da jî hin bawerîyên mîstik jî hene. Li gor Fariqî dibêje, piştî ku birayê wezîr Ebû Tahirê kurê Enbarî, Ebû'l-Xenaîm hat kuştin êvaran nûr diket ser gora wî (Fariqî, 2014:532).

Dema Sitînasa Hemdanî tînîn Amedê ku bi Ebû Elî ra bizewice li Rihayê disekinin û nîvê şevê dema Sitînas li esman dinêre ji xeybê dengekî dibihîze û wiha dibêje:"Ez li ber wî mêrî dikevim ku berî bibe zava ez bî hiştim. Li ser vê bi Sitînas ra tirs çêdibe û piştî demeke kin xebera kuştina Ebû Elî jê ra tê (Fariqî, 2014:460).

Piştî ku Mumehîduddewle bû mîr li ser xewnekê Ebû Nasir Ehmedê birayê xwe ji xwe dûr kiribû digot ez wî li ku bibînim ez ê wî bikujim. Lewra Mumehîduddewle di xew da dîtibû ku roj diket dawa Mumehîduddewle û Ebû Nasir roj ji dawa wî derdixist (Fariqî, 2014:468-469).

\section{JîYANA CIVAKî}

\subsection{Kevneşopî}

Di pirtûka Fariqî da edet û kevneşopîyên wekî pîrozkirina cejnê û girêdana şînê derbas dibin. Li gor van agahîyên Rojên cejnan gel dicivî û di hin serdeman da jî bûbû wekî eded gel roja cejnê biçe derveyê bajêr û li wir nimêja înê bike (Fariqî, 2014:457). Fariqî girtina şîna mirîyan da van agahîyan dide: Piştî ku mîr dimir wezîr, rêvebirên dewletê, carinan helbestvan û pismamên mîr dicivîyan û gel pêşwazî dikir û bi vî awayî şîna mîr gire didan. Dema Nesruddewle Ehmed mir û xelk ji bo serxweşîyê hatin cem Mîr Nizamedîn ew ji ser textê mîrîtîyê rabû û çû li erdê rûnişt û bi vî awayî mîr kesên ku ji bo serxweşîyê hatibûn, pêşwazî kirin. Piştî mirina Nesruddewle Ehmed helbestvan jî li wir amade bûn û zêmar li serê dixwendin (Fariqî, 2014:505). Ev jî nîşan dide ku di serdemama Merwanîyan da wekî kevneşopîyekê li ser mirîyan xwendina zêmaran jî heye. "Dema Mîr Nizamedîn mir wezîr û Mîr Ebû Nasir bi cilên qetîyayî û şaşika gelicî û bi cilên şînê, ji bo sersaxîyê derketin pêşberî gel" (Fariqî, 2014:517). Ev rewş jî wekî kevneşopîyeke girêdana şînê derdikeve pêşberî me.

\subsection{Weqf û Alîkarî}

Mîrên Merwanîyan girîngî didan alîkarîyê û herwiha em ji berhema Îbnu'lEzreq fam dikin ku ji bo vê weqf hatine hin çêkirin. Li gor agahîyên Fariqî di serdema Nesruddewle da Hesenê kurê Mihemedê kurê Mîxfer karûberên weqfan 
bi rê ve dibirin. Lewra Nesruddewle soz dabû ku her roj elbek genim bide feqîran. Lê tirsîya ku rojekê bi karê xwe ve mijûl bibe û vê soza xwe neyne cih. Li ser vê gazî Mihemmedê kurê Mîxfer ê berpirsyarê weqfan kir û xwest erdekî ku salê sê sed û şeşst elb dexil jê tê weqif bike. Li ser vê wî jî gundê Etşayê yê ku dikeve rojavayê Meyyafariqînê weqif kir. Ji wê rojê û vir ve jî çi dexl û danên ku ji vî gundî dihat bidestxistin li feqîran dihat belavkirin (Fariqî, 2014:478479). Li gor neqla Îbnu'l-Ezreq Nesruddewle gelek zevîyên di nav sûrên Meyyafariqînê û gelek cihên din weqif kiribûn. Xêr û alîkarîyên wisa kiribûn ku heta niha ne ji malbata wî û ne ji pismamên wî kesî xêrên bi vî awayî nekiribûn (Fariqî, 2014:477).

Di serdema Merwanîyan da ji xeynî alîkarîyê, hin rolên weqfan ên din jî hebûn. Li gor Îbnu'l-Ezreq ji bo çêkirina sûran (Fariqî, 2014:524) û vekirina qenalên avê jî hin cih hatibûn weqifkirin (Fariqî, 2014:499). Di rêvebirîya Merwanîyan da karê berpirsyarîya weqfan jî hebû lewra li gor agahîyên Îbnu'l-Ezreq piştî ku "Ebû Mensûrê kurê Şazanê Tûsî bû qazîyê Meyyafariqînê nazirtîya Weqfan jî wî dimeşand" (Fariqî, 2014:498) û ji serdema Mîr Ebû Elî û vir ve jî kesekî fileh bi navê Îbnî Şelîta mutewelîtîya weqfan dikir (Fariqî, 2014:499). "Di sala 1076an da jî Ebû Hesenê kurê Bexel bû berpirsyarê Weqfan" (Fariqî, 2014:504).

\section{Encam}

Ev berhema Îbnu'l-Ezreq a bi navê Tarîxu Meyyafariqînê di warê çand, şaristanî û avahîsazîya kurdên Merwanî da gelek agahîyan dide. Nivîskarê berhemê, Îbnu'l-Ezreq di serdema Artûqîyan da karê rêvebirîya weqfan kiriye. Bapîrê wî jî di serdema Merwanîyan de jîyaye û di rêvebirîya weqfan de xebitiye. Fariqî bi xêra vê peywira xwe derfeta ku xwe bigihîne belgeyên dewletê yên fermî bi dest xistiye. Ev taybetî girîngîya pirtûkê zêde dike.

Di warê avahîsazîyê de gelek agahî di Tarîxu Meyyafariqînê de hene. Fariqî di pirtûka xwe de Derheqê avahîyên wekî sûr, birc, keleh, qesr, pir, qub û mizgeftan de gelek melûmatan dide. Hinek ji van avahîyan niha dibînin û hinek jî wunda ne. Ev taybetîya vê pirtûkê jî dikare rê li ber xebatên nû yên avahîsazîyê bike.

Îbnu'l-Ezreq el-Fariqî di sala 1176an da berhema xwe ya bi navê Tarîxu Meyyafariqîn nivîsîye. Du destxetên vê berhemê li Londonê di Muzeya Britishê da hene. Di berhema wî da gelek mijarên derheqê dîroka Îslamê û misilmanan da hene û beşeke wê derheqê kurdên Merwanî da ye. Merwanîyan di seranserê serdema mîrnişîna xwe da di warê rêvebirîya dewletê da sîstemek ava kirine. Rêvebirî di destê mîr da ye û wezîrên wî mîrî hene. Di heman demê da bajarên derveyê paytextê bi rêya walîyan hatiye îdarekirin. Pergaleke dadmendî û darizandinê jî li cem Merwanîyan heye û ev kar bi destê qazîyan hatiye meşandin. Di warê zanist û hunerê da kar û kirinên Merwanîyan hene û gelek zana û helbestvan di nav welatê wan da jîyane. Artêşeke Merwanîyan a ku her dem amade û di bin fermana mîr da heye û serokekî vê artêşê jî heye. Di 
serdema Merwanîyan da di warê bajarvanî û avahîsazîyê da gelek xebat hatine kirin û avahîyên dîrokî hatine çêkirin. Di vê serdemê da gelek sûr, birc, keleh, qesir, pir, qenalên avê, seyrangeh, mizgeft û nexweşxane hatine çêkirin.

Di serdema Merwanîyan pergaleke aborî heye û bac hatiye berhevkirin. Li bajarên Merwanîyan bazargeh hene û bazirganî hatiye kirin. Herwiha ji serdema Bad kurê Dostik û vir ve li ser navê mir pere hatine derxistin. Kurdên Merwanî misilman û sunî ne. Wekî din fal û hin bawerîyên din ên mîstik jî li cem rêvebirên dewletê hene û kevneşopî û toreyên Merwanîyan ên ku xasî wan in jî tên dîtin. Di rêvebirîya Merwanîyan da ji bo alîkarîyê hin kar û xebat hatine kirin. Ji bo alîkarîyê û hin xizmetên din ên civakî weqf hatine sazkirin û ev kar bi rêya van weqfan hatine kirin.

\section{Çavkanî}

Baluken, Y. (2010). Mervaniler Devrinde Dinî Gruplar. Yayınlanmamış Yüksek Lisans Tezi. Van: Van Yüzüncü Y1l Üniversitesi.

Beysanoğlu, Ş.(1996). Anıt ve Kitâbeleriyle Diyarbakır Tarihi. Ankara:Diyarbakır Büyükşehir Belediyesi Kültür Sanat Yayınları.

Biçer, B. (2014). Kürtler. İstanbul: Çizgi Yayıları.

el-Hîmyerî, M.B.E. (1984). Rewdetu'l-Mutar fî̀ Xeberu'l-Eqtar (Thq. Îhsan Ebbas). Lubnan: Mektebetu'l-Lubnan.

Farqînî, Z. (2013). Türkçe-Kürtçe Sözlük. Stenbol: Estîtuya Kurdî ya Stenbolê. Îbnî Şeddad. (1978). el-Alaqû'l-Xetîre fî Zikrî Ûmerâ̂’ş-Şam we'l-Cezîre I-VII.

(Thq. Yahya Îbare). Dimeşq: Wezaratû's-Seqafîyye'l-Murşadû'l-Qewmî.

Îbnî Xelikan. (1978). Wefayatu'l-Ayan. (Thq. Îhsan Ebbas). Beyrûd Daru Sadir. İbnu'l-Ezraq. (1990). Mervanî Kürtleri Tarihi (wer. Mehmet Emin Bozarslan). Stenbol: Koral Yayınları.

Îbnu'l-Ezraq. (1990). Meyyafarikîn ve Amed Tarihi (Wer. Ahmet Savran).

Erzurum: Atatürk Üniversitesi Fen-Edebiyat Fakültesi Yayınları.

Îbnu'l-Ezreq. (1959). Tarîxu'l-Fariqî. (Thq. Bedewî Evdulletîf Awad). Qahîre:

Weşana İdaretu'l Ame's-Seqafiyye.

Îbnu'l-Ezreq. (2014). Tarîxu Meyyafariqîn (Thq. Kerîm Faruk el-Xûlî û Yusuf Baluken). İstanbul: Nûbihar.

M.S. Lazarev, Ş.X., Mihoyan, E.İ., Vasilyeva, M.A., Gasratyan, O.İ., Jigalina. (2010). Kürdistan Tarihi (Wer.İbrahim Kale). (Ed. M. S. Lazarev û Ş.X. Mihoyan). Stenbol: Avesta.

Mansız, N. (2015) İbnü'l-Esir'in el-Kamil fit't-Tarih Adlı Eserine Göre Kürtler ve yaşadıkları Bölgeler. Teza Lisansa Bilind. Muğla: Muğla Sitkı Koçman Üniversitesi.

Ripper, T. (2012). Diyarbakır Merwanileri. (Wer:Bahar Şahin Fırat). İstanbul: Avesta.

Sevim, A. (1988). Anadolu'nun Fethi Selçuklular Dönemi. Ankara: Türk Tarih Kurumu Yayınları. 
Tufantoz, A. (2005). Ortaçağda Diyarbakır Mervanoğulları. Ankara: Aça Yayınları.

Yûsuf, E. (2001). ed-Dewletu'd-Dostakîyye fî Kurdistanî'l-Wusta. (C.2.). Erbil: Darû Aras li't-tebae û neşr. 